THE TEREBELLA AND HERMELLA.

brate animals to drink themselves full, have their nearest re- skinned animals. The accompanying illustration represents

While wandering along any of our sandy coasts, we fre- lations in those which attach themselves to the exterior of the skate sucker, Pontobdella muricata (natural size). From quently come across some moderately large tubes projecting fishes and crustaceans. While, however, the free swimming the fact that it is more frequently found adhering to the from the sand, and rather conspicuous in the little puddles leeches have ringed bodies, the parasitic leeches of fish different members of the skate or ray family of fishes, it is left by the receding tide. Round their mouth is usually a and crabs have soft and smooth bodies, especially in the most commonly known as the skate sucker. This genus of set of forked filaments which, like the tube itself, are composed of fragments of sand agglutinated to gether. The substance of this habe is very soft, but very tough, and is very soft, but very tough, and without breaking. If the inhabitant of these tubes be sought, it will not be found without much labor, for the terebella retreats to the further extremity at the least indication of danger; and as the tube is a foot or more in length, and is always conducted under stones or among rocks, it is not easily dislodged.

As in the case of the sabella, this annelid performs its architectural labors by means of its tentacles, which are most wonderfully constructed; so as to be capable of extension or retraction, and at the ame time can seize or throw away a particle of sand at any part of the a particle of sand at any part of the tentacle. The is very well given by Mr. T. Rymer Jones in "Wood's Natural History:"

" If a specimen be dislodged from its tube, it swims by violent contor tions in the water, after the manner of various marine annelids; the tentaculæ and the branchiæ are tentaculæ and the branchiæ are
compressed and contracted about the head, like a brush; and as the animal is very soon exhausted by
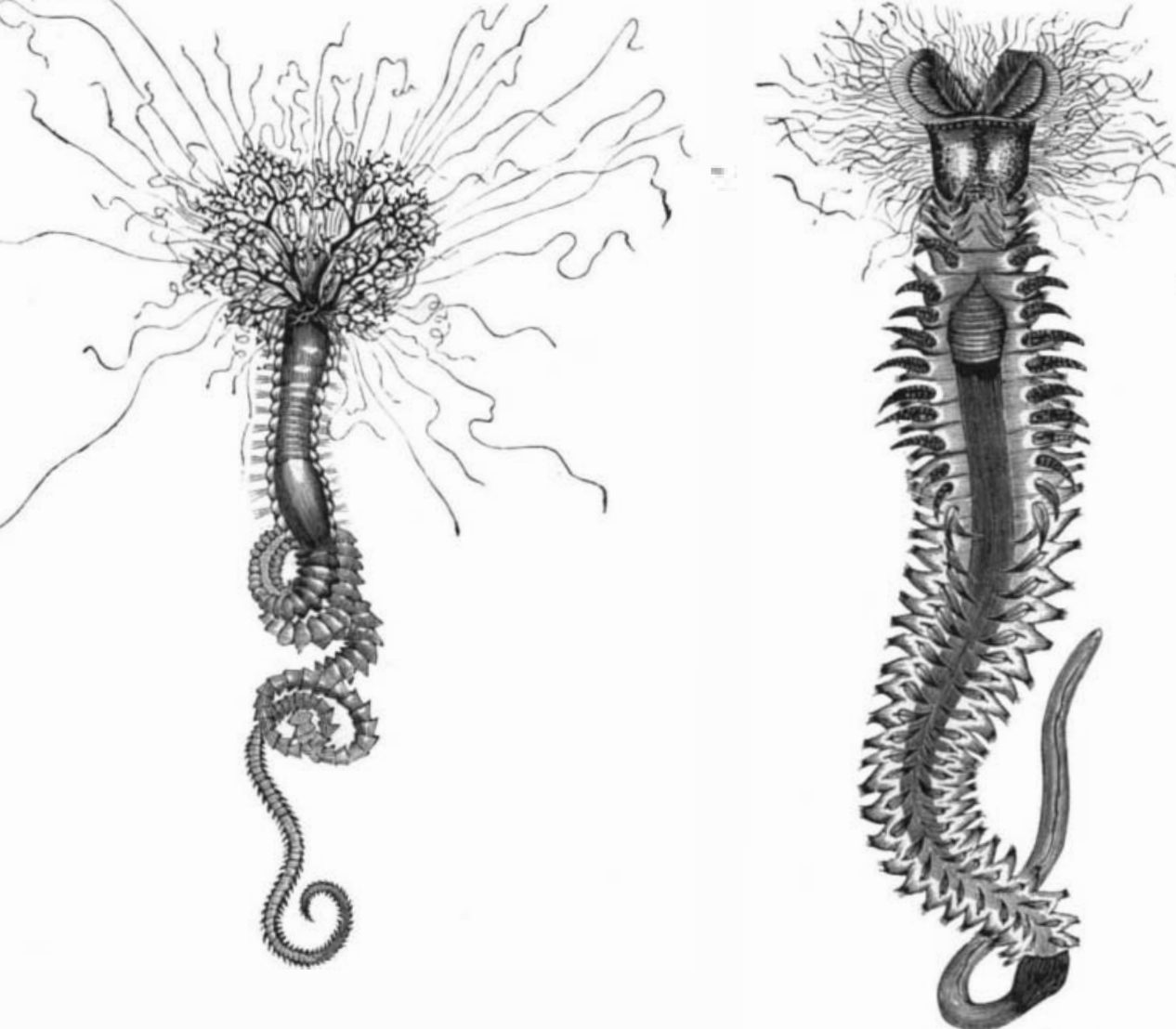

BERMELLA.-[Magnified.] marine leeches can be generally discles on the rings of the body which produce a very curiouseffect. The prevailing color of the skate sucker is a greenish gray.

These marine leeches are provided with a large and powerful suckin disk, by which they can maintain themselves in a horizontal or per pendicular position; but their most common position, when at rest and attached to inanimate objects, is a spiral, the head being in the center. On my return to the aquarium, one of the large fresh water tank which had been neglected for seve. ral months had become so infested with a small variety of parasitical leech that it was with difficulty the glass front could be kept clear of them. Even the extreme tops of the aquatic plants growing in the tank swarmed with thousands of them constantly extending themselves in their endeavors to catch on (they not being free swimmers) to the tails and fins of the lake dogfish, or the large specimen of freshwater eels contained in the tank. The eels instinctively avoided rest ing on the floor of the tank or com ing in contact with the plants or rock work sides of the tank, but remained suspended night and day in the open clear mid-water. Still, unch sot the bot om. Should a quantity of sand be now scattered from ahove, the tentaculæ, speedily relaxing, extend themselves in all directions to gather it up, sweeping the vessel quite clean, so that in a very short time not a particle is left behind that is within their reach, the whole having been collected to be employed in the construction of a new artificial dwelling, adapted to shelter the naked body of the architect.

We will suppose a tube to have been partially

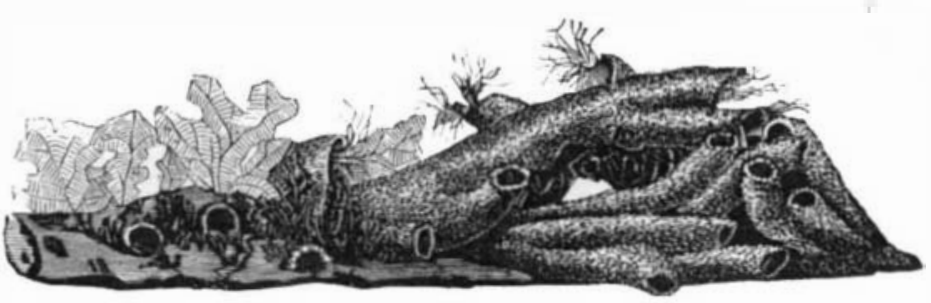

TUBES OF THE HER RHELLA.-[Natural size.] with all the precaution taken by the eels, many of them became fringed with humdreds of the leech s. I have seen the eels repeatedly loop themselves so as to bring the head and tail together, in which position they would strip off the leeches with their teelh; and in so doing they often bit or tore off small pieces of their flesh and fins, so that in course of time (when the wounds did not heal rapidly) they became badly covered with fungus. What with the leeches and the fungus the eels had become floating skeletons. To save the few remaining, constructed into the side of the aquarium wherein a speci-|Malactobdelles. In other words, there are leeches which oc-|placed them in the "hospital tank" for treatment. The course men is about to take up its permanent abode. During the casionally prey upon warm-blooded animals, and are hardly of treatment was to rapidly pass them through a bath of earlier part of the day the animal is found lurking in its to be called parasites. Others are to be found only on the warm and very salt water (a nearly saturated solution). interior, with only the extremities of the tentaculæ protrud. skin of cold-blooded vertebrates, and, finally, those of tho- This salt bath I never knew to fail in destroying lecches ing beyond the orifice, and it will so remain until towards roughly parasitic character, which adhere to crabs and soft- and fungus, if the fish so treated were not too far gone. noon. But scarcely has the sun passed the meridian than the creature begins to become restless; and towards four or five it will be seen to bave risen upwards, the tentacula ding with the approach of evening, until after sunset, when they are in full activity. They are now spread out from the cs: fice of the tube like so many slender cords; each seizes on one or more grains of sand, and drags its burden to the surnmit of the tube there the sumnit af the tube, there to be employed according to the service re quired. Should any of the tentacula slip their lold, the same organs are again employed to search eagerly for the lost particle of sand, which is again seized and dragged toward its destination.

" Such operations are protracted during several hours, though so gradually as to be apparently of little effect. Nevertheless, on resuming inspection next morning, a surprising elongation of the tule will be discovered; or, perhaps instead of a simple accession to its walls, the orifice will be surrounded by forking threads of sandy particles agglutinated together."

There are many species of terebella, There are many species of terebella,
and even on our own coasts we may be gratified with several beautiful forms of these interesting annelids. They have, to a considerable extent, the power of reproducing lost portions of the body; and it has been found that even the whole mass of plumy tentales can be removed without much incles can be remove without much injury to the terebella, which retreats to its tube, and after a while reprod
the whole of the missing organs.

\title{
FISH PARASITES.
}

The leeches which commonly swim free in the water, and only occasionally attach themselves to the bodies of verte.

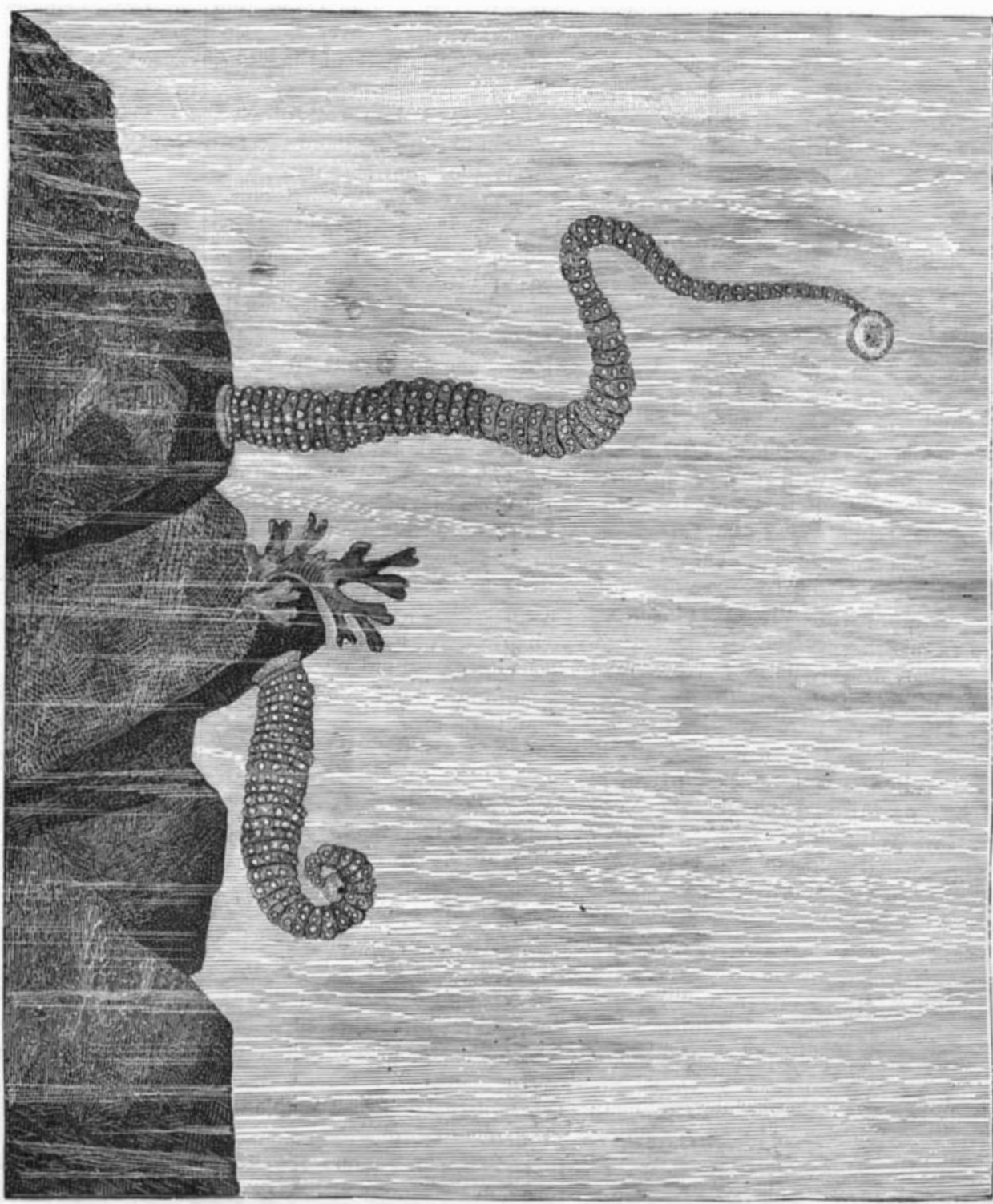

SKATE SUCKER.-Pontobdella muricata. -[Natura] șize.]
The bottom of the "hospital tank" contained i heavy flooring of Coney Island sand,in which the eels embedded themselves as if only too glad to take a rest after their long suspension. At night they were fed to repletion on raw beef. Under this treatment they soon became "solid" and happy.

The tank out of which the eels were taken was then cleared of all the fish remaining, after which a half barrel of quicklime was cast into it, and in one hour's time the lime had done its work, everything living was burnt up, the tank was then drawn off, scrubbed, and washed out, anda heavy bottom of fine sand introduced.

One of the most beautiful tanks I ever had, and of which I was very proud, contained some twenty-five weakfish, thirty kingfish, twenty striped bass, two pilotfish, and several bluefish. They were all in perfect health, high color, and feeding well. In one night all the kingfish died; the next day the weakfish departed, then the pilots, and the blues.

I had nothing in the way of an explanation, as I had never in all $\mathrm{my}$ long experience known of fish dying in this unaccountable manner. I examined the dead fish carefully; both externally and internally they appeared to be in perfect health; their gills seemed to be unusually healthy for fish kept so long in confinement.

Next to this tank was a tank of plump and healthy blackfish, who were fed as blackfish were never fed before and these, too, died in the same unaccountable manner a short time after the other fish.

Next to the blackflsh was a tank containing over one hundred spotted codlings, and who were so fat that they seldom swam for more than five 
minutes at a time without resting half an hour to take

breath

\section{!}

and day or two after the death of the weakfish, kingtish, and blackfish, the codjings began to go. Every few minutes through the day my assistant was scooping out dead fish Still I could not detect the cause, but I came to the conclu aquarium fish) die the reason ought to be discovered

All of these fish, from their first illness, had been fed on the very choicest of marine diet-soft crabs, shrimp, hard and soft clams, and even oysters and scallops. The cod- that he was wholly unable to perfect the practical applica lings would churn the surface of the water when fed on soft tions of the process, they parted company Mr Radde then cral, so keen were their appetites, and yet a minute after struck out for himself and continued the experiment, assisted
they would retire to the bottom of the tank, straighten out, by Mr. C R. Linde, a technically trained arbitect and and die I watched the codlings with painful anxiety, for gineer. By bringing to the enterprise trained skill and en I began to fear that an epidemic was spreading through the ergy that has overcome all obstacles, and by the employment entire range of tanks, and that in a few days all the fish entire range of tanks, and that in a few days all the fish
would be lost. I had noticed that when a codling began to would be lost. I had noticed that when a codling began to
die it lost its rich colors and took on a sickly brownish die it lost its rich colors and took on a sickly brownish
white color, and that its death ended in a quivering and spasmodic action, after which it would straighten out and become rigid. These are the exact symptoms of smothering Yet how could these fish die of suffocation when I was pouring oxygen into the water so rapidly that the water was of a milky color, and everything was silvery with globulcs of air?

Again I determined to make another examination, this time under a microscope, and placing a minute portion of a gill of one of the dead codlings under the glass, I was astonished to find it literally packed solid with very minute marine leeches, every one of which was gorged with blood taken from the gills of the fish. Here was the secret; these thousands of minutc parasites had so packed the delicate breathing apparatus of the fish that they had died for want of oxygen, in other words, had smothered.

Evidently these parasites were fast spreading from tank to tank; the only way to stop this was to lock up the water in the affected tanks, and thus stop the spreading of the parasites through the entire circuit of tanks and into the storage reservoirs. The few codlings that still remaned alive were treated the same as the eels, and with like good results. The locked up water was filtered through a large filter, con sisting of blankets, sponge, animal charcoal, and fine sand, sisting of blankets, sponge, animal charcoal, and fine sand,
after which it was allowed to pass into the reservoirs. I after which it was allowed to pass into the reservoirs. I
afterwards discovered that these parasites had been introafterwards discovered that these parasites had been intro-
duced into the tank through the medium of twenty five small Eastern lobsters that. in all probability, through long confinement in "cars" and smack wells, had become in being introduced in the tank.

The New Color Prining Process. Honor to whom
Hour is Due.
To the Editor of the Scientific American:

the Editor of the Scientific American:

In your issue of June 29, you repeat in an article with the title of "A New Process of Simultaneous Color Printing," certain statements which in a similar form have fallen under my eye at least a dozen times in various journals within the last six months.

So long as these statements were confined to the regular daily or weekly journals, and were referred to as items for the casual reader, I left the misstatements they embodied unnoticed, although always in the possession of facts to cor : rect them. But now as I observe their appearance in your well informed technical journal-a journal which I am happy to say is considered an authority in all technical matters by its readers-I beg to be permitted to say what I know about the very valuable and ingenious invention referred to.

The process of polychrome printing for producing com plicated color effects in one single impression-the printing from a kind of mosaic plate or ground-was the idea of many an inventive mind during the last century. Senefelder, the genial inventor of lithography, was, so far as I am aware, genial inventor of lithography, was, so far as I am aware,
the first to conceive the idea of reproducing oil paintings, the first to conceive the idea of reproducing of paintings, experiments he also invented a process which he called mo salc printing.

In the collestion of lithographic incunabula at Munic there is still to be seen "an original mosalc plate, consisting of minute sticks of color, very carefully put together, with finished and unfinished impressions taken from it." (See Ferchl, Ge.schichte der Errichtung, etc., Mïnchen, 1862.)

As Senefelder died in 1831, his priority is established be yond dispute. Experiments in this direction were followed by a Berlin artist, Liepman, who, in the first half of this century, produced reproductions of oil paintings, especially portraits, by this process, which were of wonderful accuracy. It seems, however, that he was only partially successfulthat he was unable to perfect the process so as to make it pe practically useful, and carried it only to the experimental stage; for after his first successful reproductions, of which several were regularly published, we hear no more of it Liepman also published a book describing his invention and
entitled "Der Oelgemulde Druck," Berlin, L. Sachse \& Co., 184

Similar attempts were also made in the United States. A Similar attempts were also made in the United States. A To further prove this theory, I will give an example that
firm in Maiden lane or in John street, New York, whose came under my own observation. Lightning struck a large name I cannot now remember, published some maps printed oak tree, possibly fifty rods distant from an oil well, at from mosaic blocks, a number of years ago; but the next which was a wooden tank capable of holding about 150 barand offered his American patents for my consideration terminates in the air-what is the result? A stream or of a not inconsiderable fortune, Mr Radde succeeded, about year 1876 , in making the process of real practical value It was about this time that Mr Radde wrote to me on the
ubject and sent me many beautiful specimens of his work,

After perfecting his process $\mathrm{Mr}$. Radde organized a color printing establishment in Hamburg and one in Paris, the latablishment to Mr. W. G. White. I observe in the technical papers in Germany that Mr. Greth now claims that he has reatly improved on Radde's results.

I will only add that the description of the process given in - in ain correct, and that I have no interest the matter other than that of a color printer who takes a eautiful and important art. I believe that a great field of efulness can be found for this new process in this country, now that it is being brought to the attention of the ble mention should be given to $\mathrm{Mr}$. Otto Radde and $\mathrm{Mr}$. R. Linde for their really important contribution to the Boston, June 25, 1880

Louis Prang.

\section{Another Theory for the Oll Tank Explosions.}

\section{the Editor of the Scientific American:}

I notice in your paper of July 3, 1880, an article headed "Cannonading Oil Tanks," under which you advance a cerfrom lightning.

It is unquestionat as or vapor escapes from such a body of oil, but that such conductor of electricity, we think is quite incorrect.

We give you our opinion, not as a scientist, but from a practical point, or, rather, from that which observation has us to believe.

Perhaps all of your readers may not be familiar with the facts, therefore it will require a little preliminary explanation Connected with each of these large iron tanks are a great

number of iron pipes, leading oil from great distances and
from different points into the tanks, the pipes ending ab ruptly within the tanks, which are closely covered, except at these openings or hatches in the upper parts of the tanks, where the pipes are admitted.

Now to illustrate, suppose a powerful currect of elec ricity conducted by a rod of iron to a point where the rod Just so in the case of oil tanks; at some point along these pipe lines the lightning has come in contact with some one of them. That which might be expected is just what does oc cur: the pipe line, acting as a conductor, leads it directly to and inside of the tank, where, reaching the end of the
irnn line, sparks are produced, and, of course, from the nature of sparks are produced, and, of course, from the nature of the gas contained in the tank above
explosion and terrible fire is at once produced.

You say, "Ordinary buildings, when properly provided with rods, are comparatively safe, etc., and that structures of iron, simply resting on the ground without rods, are al ways exempt from electrical damages. Such structures al ways present a continuous body of conducting material for the free passage of electricity to arth. Why is it, then, that iron oil tanks form such conspicuous exceptions to our common experience with lightning? Rods put on other masts with rods have surrounded the put on oil tanks, were exploded by lightning all the same."

Now this, together with other things I will mention, just elps to support our theory.

In the first place, we doubt whether any one can show an instance where lightning struck a tank direct. If such an
instance should occur, what would be the result ? Just as you have stated above, the iron covering would furnsh
yould an erfect conductor to the earth.

Why did not all those rods on and around the tanks pro tect them? Because the lightning did not come at those points (If it did, it would, of course, be conducted into the earth), but it came from other points, by the iron-pipe lines, directly rels ; from another well, possibly forty rods distant, an iron : ing of making the emulsion on a large scale." by lightning. tion.

Titusville, Pa , July, 1880.

To the Editor of the Screntific American: Pittsburg, Pa., July, 1880.

\section{The Oil Tank Question.} Titusville, $\mathrm{Pa}$. July, 1880 .

\section{The Relative Cost of Motive Power.} pertained principally to small motors. imes as expensive as the 100 horse power steam engine.

\section{A New Photo Emulsion.}

pipe led the oil to this tank also Immediately after the tree was struck this tank was on fire. Fortunately but little oll was in the tank, and before the fire had consumed the gas sufficient to reach the oll (as there was but lit tle chance (he fo signs or marks of lightning could be traced, either about the derrick or on the building with cover containing the hatch. It seemed positive that the line conveyed the electricity iuto the tank, thereby igniting the gas. Possibly this theory is not correct and I would be Knox P. O, Clarion Co, $\mathrm{Pa}$. July, 1880 F. G. SACkET,

\section{oil Tanks Struck by wightning.}

In your issue of July 3 you say that " lightning is pecu-
In the of the Scientific American : larly attracted by ron oil tanks, causing disastrous fires." This seems contrary to our experience as well as our philosophy The tank struck here June 11 was not an iron ank, but was one of the old fashioned tanks with wooden were destroyed here at that time, but they were not ignited

Your theory about the ascending column of vapor attract ing the electric current has no doubters in these parts; bu we fall to see why the lightning would not leave the oil vapor and oll if such a splendid conductor as a 20,000 barrel oll tank, bult entirely of boiler iron and sunk well into the round, was interposed, especially if the iron tank was con nected, as tanks in this country are, with pipe lines many

I notice your article about lightning being attracted by the iron oil tanks. The remedy for this has been found long since. The use of the iron top instead of wood. There has
never been a tank of oil with iron top burned by lightning. D. B. Mason.

To the Editor of the Scientific American:
I have read your remarks referring to our late oil fire here, and giving a reason or explanation of the cause of it. think you are out of the way in your statement, for the sphere and rather fear this most in and about a refinery, as these vapors hug. ging the ground are frequently drawn toward their furnace fires and lead to fearful explosions. Then the tops of these iron tanks are generally if not always tight, it being as necessary to keep out rain as to keep in the oil and vapor. In 7 o'clock in instance the lightning struck this tank at ny vapor to speak of; and these tanks are often struck in winter time, when the atmosphere is not warm enough to ause the vapors to be generated. Then, too, why is it that ron tanks with iron tops are not struck by lightning, while hose of wood tops (covered with turf) are. I am anxious to get at the cause, and have written this solely to bring out

Mr. Bissinger, M.E., at Carlsruhe, Germany, gives the following results as obtained in his examinations of the several motors in regard to the relative cost per horse power
for each hour. It will be observed that the eximination

The relative cost per effective horse power per hour is as

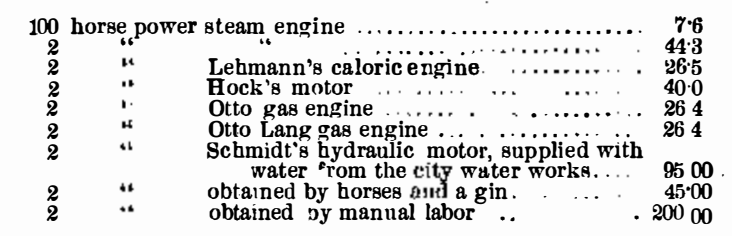

Otto's gas motor and Lehmann's caloric engine are the cheapest of the small motors, but are, nevertheless, four

( A dvantage of gelatine emulsion (high sensitiveness) with the dvantages of collodion emulsion. It appears to keep any ength of time, and, best of all, it may be poured like col. lodion upon the glass, drying as quickly as the latter. The plates are developed, intensified, fixed, and washed exactly like collodion plates, and dry like these. Moreover, the film may be exposèd in the camera seven minutes after prepara. tion and before drying. You will be glad to hear that sev-
eral of our Berlin photographers-Prumm, Schaarwachter, eral of our Berlin photographers-Prumm, Schaarwachter,
and Reichard-have tried the emulsion, and reported upon its success to the Society for the Advancement of Photo. 